Tjalling C. Koopmans Research Institute

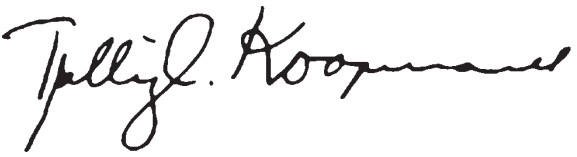

Discussion Paper Series nr: 05-05

Horizontal integration in markets for complementary components and vertical product differentiation:

A case-based analysis in the semiconductor industry

Bastian Westbrock 


\section{Tjalling C. Koopmans Research Institute Utrecht School of Economics \\ Utrecht University}

Vredenburg 138

3511 BG Utrecht

The Netherlands

telephone $\quad+31302539800$

fax $\quad+31302537373$

website www.koopmansinstitute.uu.nl

The Tjalling C. Koopmans Institute is the research institute and research school of Utrecht School of Economics.

It was founded in 2003, and named after Professor Tjalling C. Koopmans, Dutch-born Nobel Prize laureate in economics of 1975.

In the discussion papers series the Koopmans Institute publishes results of ongoing research for early dissemination of research results, and to enhance discussion with colleagues.

Please send any comments and suggestions on the Koopmans institute, or this series to M.Damhuis@econ.uu.nl

ontwerp voorblad: WRIK Utrecht

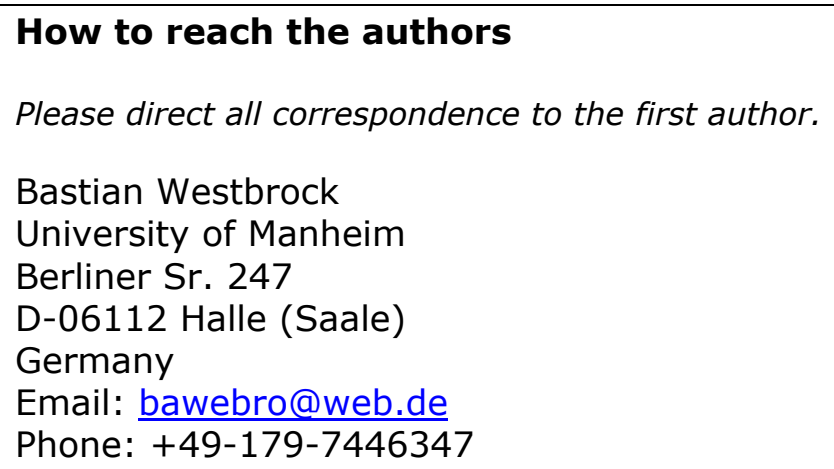

This paper can be downloaded at: http://www.koopmansinstitute.uu.nl 


\title{
Horizontal integration in markets for complementary components and vertical product differentiation: A case-based analysis in the semiconductor industry*
}

\author{
Bastian Westbrock \\ ${ }^{a}$ University of Manheim
}

07 November 2004

\begin{abstract}
Observations of recent mergers and acquisitions (M\&A) in the semiconductor and computer industry indicate that activities concentrate on the technology leaders in this market. The author examines the influence of players' heterogeneous product technologies on their involvement in M\&A. He provides a rationale for the influence with the help of a case study and a two-stage non cooperative game. The case is about an acquisition wave between suppliers in two semiconductor component markets. Exemplary for the whole industry, acquisition activities concentrated on the technology leader in one of the component markets. Technological heterogeneity is represented within a vertically differentiated product space in the model.
\end{abstract}

Keywords: semiconductor industry, computer industry, horizontal integration, complementary product, product differentiation

JEL classification: L11, L13, L63

Acknowledgements

I thank Stefan Lutz, Konrad Stahl, and Georg Licht for helpful comments and suggestions as well as the ZEW for its hospitality.

\footnotetext{
* The paper is based on my diploma thesis "Horizontal integration in markets for complementary inputs", which I submitted at the department of Economics, University of Mannheim in Mai 2004. See Westbrock (2004).
} 


\section{Introduction}

The semiconductor and computer industry is characterized by a large number of M\&A in recent years. ${ }^{2}$ Most of the deals concentrate on well-known players like Intel, 3Com, Apple Computers, and Broadcom, who occupy positions of acquiring parties or dominating partners. ${ }^{3}$ Intel Corporation, the world-leading semiconductor component supplier for computers, for example, had a list of 75 deals in a seven-year period. Its competitors in the market for Central Processor Units (CPUs), in contrast, were involved in not more than six M\&A. Common to the group of well known players is that they all have heavily promoted progress in semiconductor and computer technologies. All of them occupy the position of the technology leader in their specific market. ${ }^{4}$

The paper contributes an explanation on the phenomenon that technology leaders are involved in most of the M\&A in the semiconductor and computer industry. The focus is on the rationale for the specific type of horizontal M\&A between suppliers for complementary products, which plays an important role in the industry. ${ }^{5}$

With the help of a case study about some representative horizontal M\&A, the author conducts an investigation into the concentration phenomenon. The case deals with a wave of acquisitions between suppliers in two component markets for laptop computers. These are the market for mobile CPUs, an adjustment of desktop CPUs, and the market for Wireless Local Area Network (WLAN)

\footnotetext{
${ }^{2}$ See OECD (2002), p. 94 for detailed numbers.

${ }^{3}$ A data collection about M\&A in selected computer hardware markets in the period from 1989 to 2003 reveals that just eight players were involved in 167 deals out of a total of 228. Data is gathered from the Mergerstat M\&A Database and Hoover's Company Profiles, which are available on Lexis-Nexis, an Internet meta-database on legal, business, and economic sources.

${ }^{4}$ See Hoover's Company Profiles.

5 A systematization of Intel's deals shows that most of its targets were companies with main product lines in other positions of the value chain than Intel's. It had 18 horizontal M\&A targeting suppliers for substitutes. However,

57 M\&A resulted in a vertical expansion in the value chain or a horizontal expansion into another component market.
} 
chips, which is a component especially designed for mobile computing. ${ }^{6}$ Intel has the position of the technology leader in the market for mobile CPUs and exemplary for the industry activities, Intel also dominated in the observed acquisition wave.

A two-stage non-cooperative game with M\&A decisions in the first stage and quantity competition in the second provides a rationale for the case. ${ }^{7}$ Technological heterogeneity of the players is represented within a vertically differentiated product space, which is introduced by Gabszewicz \& Thisse (1979) and Shaked \& Sutton (1982) in the literature. The players' differentiated positions within the product space cause the equilibrium industry structures to be asymmetric, when some but not all firms are involved in M\&A. Although the model is of static nature in the sense that product and process innovation do not take place, it represents the context of the semiconductor and computer markets. Chip suppliers are highly specialized in development and manufacturing. Therefore, final goods are comprised of essential components, which are provided by monopolistically competitive, single-good producers. The compatibility of components' interfaces is confirmed by industry consortia in these industries.

The existing literature about horizontal M\&A between suppliers for complementary products cannot provide insight into the concentration phenomenon. Economides (1994) and Church \& Gandal (2000) examine equilibrium industry structures of integrated and independent firms. However, they do not introduce heterogeneities in the players' technologies and therefore, they obtain symmetric equilibria, which do not allow the identification of integrated and independent players.

\footnotetext{
${ }^{6}$ A Wireless LAN is one, in which a mobile user can connect to a local area network through a wireless (radio) connection. A WLAN chip is the logic circuitry in a computer that transmits the outgoing and incoming instructions as well as data. Chip is a short form for microchip, the small and complex modules that store computer memory or provide logic circuitry.

${ }^{7}$ In the context of the model, mergers and acquisitions have the same effects on industry structures, profits of the parties involved, and market prices. Thus, in the analytical parts of the paper, the terms are used synonymously.
} 
The paper also evaluates the effect of a vertically differentiated product space on social desirability of horizontal mergers. According to the literature, one could expect two contrary outcomes. The first, welfare-enhancing refers to Cournot (1960). ${ }^{8}$ In his model, a merger reduces the price for a bundle of complementary components due to the fact that two firms, each offering one of the goods, ignore the effect of independent pricing on the residual demand of each other. The integrated supplier internalizes the 'horizontal externality' and reduces the bundle price. ${ }^{9}$ Church \& Gandal (2000) and Church \& Ware (2000) investigate a foreclosure effect. ${ }^{10}$ Given that the merged firm refuses to sell its components separately, a component supplier in the target market of the merger is eliminated. This allows the remaining independent firms to gain market power and hence, lowers the revenues rivals achieve in the market of the merging firm. Consumer prices increase due to market foreclosure. The paper provides another effect of horizontal M\&A on consumer prices and outsiders' profits. The effect stems from the introduction of vertically differentiated products and heterogeneous consumer preferences in the model.

The paper is organized as follows: the case of the acquisition wave is introduced in the second section. The model setup and calculations follow in the third. Section four and five provide the results about the concentration phenomenon and its welfare implications. In the sixth section, the results are investigated for robustness to changes in the most critical assumptions. Section seven summarizes and concludes about extensions for the application of the model.

\footnotetext{
${ }^{8}$ Cournot (1960) is an English translation of the original Cournot (1838): Researches sur les principes mathématiques de la théorie des richesses. See also Shapiro (1989), pp. 339-340 for a formalized summary of chapter 9 of Cournot's work, which is referred to here.

${ }^{9}$ Economides \& Salop (1992) and Economides (1994) generalize the analysis to duopolies in each of the component markets.

${ }^{10}$ See Church \& Ware (2000), pp. 625-641.
} 


\section{A wave of acquisitions between suppliers for laptop-computer components}

From 1999 to 2002, a group of suppliers for desktop and laptop CPUs acquired various designers for WLAN chip technology. Table 1 depicts the timeline of acquisitions and Table 2 the CPU suppliers' performance after the wave. Paradoxically, the acquisitions occurred in an industry, in which the highly specialized company is the typical player. Not only are there specialists for specific components, but also the design and manufacturing functions are performed by separate companies as well. ${ }^{11}$

\begin{tabular}{|l|cccc|}
\hline & $\begin{array}{c}\text { Acquiring } \\
\text { company }\end{array}$ & $\begin{array}{c}\text { Main product } \\
\text { line }\end{array}$ & Target company & Main product \\
& Intel & CPUs & Dialogic & (W-)LAN chips \\
July 1999 & Intel & CPUs & Level One & WLAN chips \\
March 2001 & Intel & CPUs & Xircom & WLAN chips \\
February 2002 & AMD & CPUs & Alchemy SC & (W-)LAN chips \\
May 2002 & VIA & CPUs & LSI Logic Chip & (W-)LAN chips \\
\hline \hline
\end{tabular}

Table 1: Timeline of acquisitions (Source: Mergerstat M\&A Database)

Especially Intel was involved in a lot of these acquisitions. It was this company that started the wave in 1999, and the only one that acquired until 2002. Total deal value amounted to more than $\$ 4.2$ billion with investments of about $\$ 4.1$ billion by Intel alone.

What had happened that could have caused the acquisition wave? And more importantly, how can we explain Intel's dominance within the wave?

\footnotetext{
${ }^{11}$ See Macher, Mowery \& Hodges (1998), pp. 119-120.
} 
In the end of the 1990s, technology breakthroughs in the areas of micro-architecture, liquid crystal displays, and wireless data transfer devices have made mobile computing affordable to mass markets. ${ }^{12}$ Households and businessmen shifted preference from desktop computers to the more expensive, but also more sophisticated, laptops. ${ }^{13}$ Since then, the laptop market has been one of the fastest growing of all computer markets.

\begin{tabular}{|l|ccc|}
\hline \hline Company & $\begin{array}{c}\text { Revenue (\$mil.) } \\
\text { by product line in 2002 }\end{array}$ & $\begin{array}{c}\text { Market share in } \\
\text { CPU market in 2002 }\end{array}$ & $\begin{array}{c}\text { Profit (\$mil.) } \\
\text { by product line in 2002 }\end{array}$ \\
\hline Intel & CPUs and related & & CPUs and related \\
AMD & 22,316 & $82 \%$ & 6,562 \\
IBM & CPUs and related & & CPUs and related \\
& 2,663 & $16.8 \%$ & -846 \\
VIA & technology product line & & all product lines \\
Transmeta & CPU product line & $0.8 \%$ & 3,579 \\
& 0.024 & $0.3 \%$ & all product lines \\
& all product lines & & 13 \\
\hline \hline
\end{tabular}

Table 2: Revenues, market shares, and profits of CPU suppliers (Sources: Hoover's Company Profiles, Extel Cards, and Heise.de)

Due to the technological progress and the introduction of the first industry-wide wireless communication standard 802.11 by the Institute of Electrical and Electronics Engineers (IEEE) in 1999, a self-contained market for WLAN chips established during that time. In the year of

\footnotetext{
${ }^{12}$ See OECD (2002), pp. 221-234.

${ }^{13}$ See Tech Europe (2004).
} 
establishment, 23 suppliers for communication and network technologies, with 3Com, Broadcom, and Nortel Networks being important names among them, started the production of WLAN chips according to the 802.11 standard.

Technological progress in the market for CPUs, in contrast to drastic developments in the WLAN chip market, could be denoted as a 'path of incremental innovations'. The mobile CPU technology is just an adjustment of desktop CPUs to the requirements of laptop computing. It is lower in energy consumption and smaller in size, but it lags in calculation performance.

Intel was the first who introduced mobile CPUs, starting with its Pentium III Mobile series. According to reports of industry experts, Intel and its recent Centrino technology are still ahead in competition for technology leadership against archrival AMD. ${ }^{14}$ Its competitors IBM, VIA Technologies, and Transmeta lag behind. Table 2 indicates that Intel's leadership is also reflected in performance measures. In 2002, the company's market share for CPUs was about $82 \%$, followed by AMD with $16.8 \%$. The other suppliers shared not more than $1.2 \%$.

The model, developed in the next section, provides a rationale for the observations. The focus is on the explanation of the industry formation in the period from 1999 to 2001, when only Intel was integrated into the WLAN chip industry.

${ }^{14}$ See C't (2002), p. 100 and THG (2004). 


\section{The model}

The model bases on two assumptions that abstract from the observed acquisition wave and the observed supplier structure. First, the scope of analysis is restricted to the two dominating companies in the CPU market, Intel and AMD. Second, each of them is allowed to acquire at most one of the WLAN chip suppliers.

The setup is investigated in a two-stage game with acquisitions in the first and quantity competition in the second stage. The players are Intel, which is denoted by $\mathrm{i}=\mathrm{h}$, and AMD, which is denoted by $i=1$. In the market for WLAN chips, there is an arbitrary number of $n \geq 2$ suppliers, which are involved in quantity competition of stage two. However, they are only targets of acquisitions in stage one. An arbitrary firm in that market is denoted by j. Entry from a third party is assumed to be blocked in both component markets. ${ }^{15}$

\section{Technology:}

The CPU suppliers offer each a single, vertically differentiated product, which satisfies the condition that the quality of the superior CPU is larger than the quality of the inferior $\left(\mathrm{s}_{\mathrm{h}}>\mathrm{s}_{\mathrm{l}}\right)$. Alternatively, we rewrite $\mathrm{s}_{\mathrm{h}}$ emphasizing the relative quality distance from $\mathrm{s}_{1}$ :

$$
\mathrm{s}_{\mathrm{h}}:=s s_{l} \quad \text { and } \quad s>1
$$

Considering the free-access guarantee of the IEEE to the pool of necessary intellectual properties to produce WLAN chips, we assume that all chips are of homogeneous quality, which is denoted by $\mathrm{s}_{\mathrm{j}}$. In addition, the IEEE 802.11 standard ensures that WLAN chips are fully compatible with both CPUs if the components are offered by separate suppliers. However, it is assumed that a player,

\footnotetext{
${ }^{15}$ An administrative complaint of the U.S. Federal Trade Commission against Intel outlines the entry barriers into the market for CPUs: an entrant would have to spend about $\$ 250$ million to start up the design of a state-of-the-art chip. Development of the first product would require at least four years, which is a very long time in the computer markets. See FTC (2004). It is hard to justify the assumption of entry barriers into the market for WLAN chips, since the IEEE guarantees free access to the pool of necessary intellectual properties to produce WLAN chips. See IEEE (2004). Thus, we assume that access to the pool requires being an original member of the IEEE. Access of later entrants is denied.
} 
which is integrated into both component markets, offers exclusively integrated bundles. Without any loss of generality, marginal costs of producing semiconductor chips are assumed to be zero.

The assumptions about the game structure and the technology result in four possible industry structures underlying the subgame of stage two. Independence of both players is denoted by (S,S), partial integration of the high-quality supplier by (S,I), partial integration of the low-quality supplier by (I,S), and total integration by (I,I).

\section{Demand functions:}

Consumers have preferences over component bundles (laptop computers), and they have to purchase a bundle comprised of both essential components to derive any utility from them. ${ }^{16}$ Thus, a consumer buys a complete bundle or nothing. From the former alternative she derives gross utility, which is the product of the components' qualities. From the latter she extracts utility of zero from an outside alternative, competitively supplied desktop computer. A consumer's preference function is: ${ }^{17}$

$$
\mathrm{U}\left(\theta_{\mathrm{k}}, i j\right)=\left\{\begin{array}{l}
\theta_{\mathrm{k}}\left(s_{h} s_{j}\right)-p_{h j} \\
\theta_{\mathrm{k}}\left(s_{l} s_{j}\right)-p_{l j} \\
0
\end{array} .\right.
$$

$\mathrm{p}_{\mathrm{ij}}$ denotes $\left(\mathrm{p}_{\mathrm{i}}+\mathrm{p}_{\mathrm{j}}\right)$ if components are offered by separate suppliers, and it denotes $\mathrm{p}_{\mathrm{i}}$ given that a bundle is produced by an integrated CPU supplier. $\theta_{\mathrm{k}}$ denotes an income or taste parameter. Because of homogeneous WLAN chips, there are only two different laptop computers from the

\footnotetext{
${ }^{16}$ It is intuitive that a CPU is essential for assembling a laptop because of technical reasons. Assuming essentiality of a WLAN chip is not straightforward, since the feature of wireless networking is not more than just an add-on to laptop computers. However, consumers do not extract particular utility from laptops with stand-alone CPUs, but prefer the wireless networking feature because of its extra utilities. Considering this, WLAN chips are essentials for laptop computers in the sense that they provide the key characteristics in consumer purchasing decisions between laptops and the cheaper desktop computers.

${ }^{17}$ Consumer preferences and derivation of the demand system are motivated by Tirole (1988).
}

See Tirole (1988), pp. 96-97. He provides a simplified version of the heterogeneous preferences in Shaked and Sutton (1982). 
consumers' perspectives. All consumers agree about superiority of a bundle with Intel's CPU, but they differ in their payment reserves to obtain the high-quality laptop. These heterogeneous preferences are reflected by the income parameter $\theta_{\mathrm{k}} \in[a, b]$. It is a positive, real number, which is uniformly distributed across the population of consumers with a density of one. We normalize $\mathrm{b}=\mathrm{a}+1$ for simplicity. High-income consumers establish the high-quality segment of demand; lowincome consumers establish the low-cost segment.

Suppliers' demand is limited by the residual consumers, which they attract. From the incentive compatibility constraint we derive the income parameter of the residual consumer who is indifferent between buying a bundle with the superior CPU and a bundle with the inferior chip:

$$
\bar{\theta}=\frac{p_{h j}-p_{l j}}{s_{j}\left(s_{h}-s_{l}\right)}
$$

The income parameter of the residual consumer, who is indifferent between purchasing the lowquality bundle and nothing, is obtained by applying the participation constraint: ${ }^{18}$

$$
\underline{\theta}=\frac{p_{l j}}{s_{j} s_{l}}
$$

The constraints determine a generic system of residual demand functions for the CPU suppliers, which is applicable to all industry structures:

$$
\begin{aligned}
& q_{l}=\frac{p_{h j}-p_{l j}}{s_{j}\left(s_{h}-s_{l}\right)}-\frac{p_{l j}}{s_{j} s_{l}} \\
& q_{h}=b-\frac{p_{h j}-p_{l j}}{s_{j}\left(s_{h}-s_{l}\right)}
\end{aligned}
$$

The high-quality firm serves the high-quality segment of demand; the low-quality firm sells to the low-cost segment. The shape of the total demand function for the suppliers in the WLAN chip market depends on the industry structure. Under independence, it is the sum of the CPU suppliers'

\footnotetext{
${ }^{18}$ We do not require $\underline{\theta}$ being identical with the income of the poorest consumer. Thus, the potential market has not to be covered.
} 
residual demand. Under partial integration, it is the residual demand of the independent CPU supplier. Since all WLAN chips are of homogenous quality, every chip is sold at the unique market price $\mathrm{p}_{\mathrm{n}}$, which is the minimum of the individual WLAN chip suppliers' prices. At the market price, the firms share total demand in equal proportions.

In the industry structure of independence, for example, demand functions are:

$$
\begin{aligned}
q_{l} & =\frac{p_{h}-p_{l}}{s_{j}\left(s_{h}-s_{l}\right)}-\frac{p_{l}+p_{n}}{s_{j} s_{l}} \\
q_{h} & =b-\frac{p_{h}-p_{l}}{s_{j}\left(s_{h}-s_{l}\right)} \\
q_{n} & =q_{l}+q_{h} \\
q_{j} & =\frac{1}{n} q_{n} .
\end{aligned}
$$

Under partial integration of the superior firm, they change to:

$$
\begin{aligned}
& q_{l}=q_{n-1}=\frac{p_{h}-\left(p_{l}+p_{n-1}\right)}{s_{j}\left(s_{h}-s_{l}\right)}-\frac{p_{l}+p_{n-1}}{s_{j} s_{l}} \\
& q_{h}=b-\frac{p_{h}-\left(p_{l}+p_{n-1}\right)}{s_{j}\left(s_{h}-s_{l}\right)} \\
& q_{j}=\frac{1}{n-1} q_{n-1} .
\end{aligned}
$$




\section{Quantity competition in the second stage:}

In the second stage of the game, competition is in quantities, and all firms are allowed to exploit oligopolistic market power. Hence, component prices and especially the market price for WLAN chips contain mark-ups on marginal costs. The system of inverse demand functions for quantity competition is determined by: ${ }^{19}$

$$
p_{i}\left(q_{i}, p_{n}\right) \text { and } p_{n}\left(q_{j}\right) \quad, i=h, l \text { and } j=1, \ldots, n \text {. }
$$

Firms' profit functions are:

$$
\begin{aligned}
& \pi_{i}=p_{i} q_{i} \\
& \pi_{j}=p_{n} q_{j} .
\end{aligned}
$$

Determination of Nash-equilibrium quantities is straightforward under all industry structures. ${ }^{20}$

Table 3 summarizes equilibrium quantities and operating profits.

\footnotetext{
${ }^{19}$ In the model, the suppliers in the WLAN chip market determine quantities before the players in the CPU market move. Simultaneous quantity setting is impossible in the simple setup because of the coordination problem that the same amount of essential components cannot be independently set by players with just almost perfect information and without stock keeping capabilities.

${ }^{20}$ See Westbrock (2004) for the derivation.
} 


\begin{tabular}{|c|c|c|}
\hline Independence: & & \\
\hline$\hat{q}_{l}^{(s, s)}=b \frac{2 s^{2}(n-2)+5 s-1}{2 s(4 s-1)(1+n)}$ & $\hat{p}_{l}^{(s, s)}=b \frac{s_{l} s_{j}\left(2 s^{2}(n-2)+5 s-1\right)}{2 s(4 s-1)(1+n)}$ & $\hat{\pi}_{l}^{(s, s)}=b^{2} \frac{s_{l} s_{j}\left(2 s^{2}(n-2)+5 s-1\right)^{2}}{4 s^{2}(4 s-1)^{2}(1+n)^{2}}$ \\
\hline$\hat{q}_{h}^{(s, s)}=b \frac{4 s^{2}(n+1)-s(5+2 n)+1}{2 s(4 s-1)(1+n)}$ & $\hat{p}_{h}^{(s, s)}=b \frac{s_{l} s_{j}\left(4 s^{2}(n+1)-s(5+2 n)+1\right)}{2(4 s-1)(1+n)}$ & $\hat{\pi}_{h}^{(s, s)}=b^{2} \frac{s_{l} s_{j}\left(4 s^{2}(n+1)-s(5+2 n)+1\right)^{2}}{4 s(4 s-1)^{2}(1+n)^{2}}$ \\
\hline$\hat{q}_{j}^{(s, s)}=b \frac{3 s-1}{(4 s-1)(1+n)}$ & $\hat{p}_{n}^{(s, S)}=b \frac{s_{l} s_{j}(3 s-1)}{2 s(1+n)}$ & $\hat{\pi}_{j}^{(s, s)}=b^{2} \frac{s_{l} s_{j}(3 s-1)^{2}}{2 s(4 s-1)(1+n)^{2}}$ \\
\hline Partial integration of $\mathrm{i}=1$ : & & \\
\hline$\hat{q}_{l}^{(I, s)}=b \frac{2 s n+2 s-1}{2 n(4 s-1)}$ & $\hat{p}_{l}^{(I, S)}=b \frac{s_{l} s_{j}(2 s n+2 s-1)}{2 n(4 s-1)}$ & $\hat{\pi}_{l}^{(I, S)}=b^{2} \frac{s_{l} s_{j}(2 s n+2 s-1)^{2}}{4 n^{2}(4 s-1)^{2}}$ \\
\hline$\hat{q}_{h}^{(I, S)}=b \frac{(n-1)(2 s-1)}{n(4 s-1)}$ & $\hat{p}_{h}^{(I, S)}=b \frac{S S_{l} S_{j}(n-1)(2 s-1)}{n(4 s-1)}$ & $\hat{\pi}_{h}^{(I, S)}=b^{2} \frac{s s_{l} s_{j}(n-1)^{2}(2 s-1)^{2}}{n^{2}(4 s-1)^{2}}$ \\
\hline$\hat{q}_{j}^{(I, S)}=b \frac{2 s-1}{n(4 s-1)}$ & $\hat{p}_{n-1}^{(I, S)}=b \frac{s_{l} s_{j}(2 s-1)}{2 n(4 s-1)}$ & $\hat{\pi}_{j}^{(I, S)}=b^{2} \frac{s_{l} s_{j}(2 s-1)^{2}}{2 n^{2}(4 s-1)^{2}}$ \\
\hline Partial integration of $\mathrm{i}=\mathrm{h}$ : & & \\
\hline$\hat{q}_{l}^{(s, I)}=b \frac{s(n-1)}{n(4 s-1)}$ & $\hat{p}_{l}^{(S, I)}=b \frac{s S_{l} s_{j}(n-1)}{n(4 s-1)}$ & $\hat{\pi}_{l}^{(s, I)}=b^{2} \frac{s^{2} s_{l} s_{j}(n-1)^{2}}{n^{2}(4 s-1)^{2}}$ \\
\hline$\hat{q}_{h}^{(S, I)}=b \frac{4 s n-2 n+1}{2 n(4 s-1)}$ & $\hat{p}_{h}^{(S, I)}=b \frac{S s_{l} s_{j}(4 s n-2 n+1)}{2 n(4 s-1)}$ & $\hat{\pi}_{h}^{(s, I)}=b^{2} \frac{s s_{l} s_{j}(4 s n-2 n+1)^{2}}{4 n^{2}(4 s-1)^{2}}$ \\
\hline$\hat{q}_{j}^{(S, I)}=b \frac{s}{n(4 s-1)}$ & $\hat{p}_{n-1}^{(S, I)}=b \frac{S_{l} S_{j}}{2 n}$ & $\hat{\pi}_{j}^{(S, I)}=b^{2} \frac{s_{l} S_{j} S}{2 n^{2}(4 s-1)}$ \\
\hline Total integration: & & \\
\hline$\hat{q}_{l}^{(I, I)}=b \frac{s}{4 s-1}$ & $\hat{p}_{l}^{(I, I)}=b \frac{S_{l} S_{j} S}{4 s-1}$ & $\hat{\pi}_{l}^{(I, I)}=b^{2} \frac{s_{l} s_{j} s^{2}}{(4 s-1)^{2}}$ \\
\hline$\hat{q}_{h}^{(I, I)}=b \frac{2 s-1}{4 s-1}$ & $\hat{p}_{h}^{(I, I)}=b \frac{s_{l} s_{j}(2 s-1)}{4 s-1}$ & $\hat{\pi}_{h}^{(I, I)}=b^{2} \frac{s_{l} s_{j} s(2 s-1)^{2}}{(4 s-1)^{2}}$ \\
\hline
\end{tabular}

Table 3: Subgame equilibrium quantities and operating profits 


\section{A bargaining game in the first stage:}

In the first stage of the game, Intel and AMD decide about an acquisition of (or a merger with) at most one of the independent WLAN chip suppliers. An acquisition is profitable if the operating profit of the resulting integrated supplier, net of any costs of integration, makes both firms better off. It is assumed that the target company is compensated for the foregone profit that it received before the acquisition. The players obtain the residuum of the integration but in the case of acquiring, they have additional fixed costs, which represent disadvantages of foregone specialization in production.

Formally, the players are involved in a one-shot bargaining game. They choose simultaneously between strategies from the set $\mathrm{A}_{\mathrm{i}}=$ [Integration, Separation]. Let $\mathrm{a}=\left[\mathrm{a}_{\mathrm{i}}, \mathrm{a}_{\mathrm{i}}\right]$ be a strategy profile. Such a profile determines an industry structure of integrated and independent players and the firms' operating profits. Players' payoffs associated with the strategies are given by:

$$
\begin{aligned}
& v_{i}\left(a_{i}, a_{-i}\right)=\pi_{i}^{\left(a_{i}=S, a_{-i}\right)} \quad \text { if } a_{i}=S \\
& v_{i}\left(a_{i}, a_{-i}\right)=\pi_{i}^{\left(a_{i}=I, a_{-i}\right)}-\pi_{j}^{\left(a_{i}=S, a_{-i}\right)}-F \quad \text { if } a_{i}=I \text {. }
\end{aligned}
$$

The solution concept of the bargaining game is the perfect Nash equilibrium of the two stage game. Therefore, the sufficient condition for an equilibrium of total independence is:

$$
\text { (1) } v_{l}(I, S)-v_{l}(S, S)<0 \text { and } v_{h}(S, I)-v_{h}(S, S)<0 \text {. }
$$

For an equilibrium of partial integration of the low-quality supplier, it is sufficient that:

$$
\text { (2) } v_{l}(I, S)-v_{l}(S, S) \geq 0 \text { and } v_{h}(I, I)-v_{h}(I, S)<0 \text {, }
$$

For an equilibrium of partial integration of the high-quality supplier:

$$
\text { (3) } \quad v_{l}(I, I)-v_{l}(S, I)<0 \text { and } v_{h}(S, I)-v_{h}(S, S) \geq 0
$$

is a satisfying condition, and for total integration:

(4) $\quad v_{l}(I, I)-v_{l}(S, I) \geq 0$ and $v_{h}(I, I)-v_{h}(I, S) \geq 0$. 


\section{Explanation of the acquisition wave}

The section presents the rationale for the effect of a demand shift on the incentives for M\&A as well as for the influence of players' technological heterogeneities on their M\&A activities. A characterization of the equilibrium industry structures of the model reveals insight into this. ${ }^{21}$

\section{The effect of a demand shock:}

Corollary 1: A positive demand shock switches the equilibrium industry structure from independence to partial integration and from that structure to total integration.

Proof: The increasing income parameter of the wealthiest consumer represents the demand shock rather appropriate. Its effects on the industry-structure conditions are:

$$
\frac{\partial\left[v_{i}\left(a_{i}=I, a_{-i}\right)-v_{i}\left(a_{i}=S, a_{-i}\right)\right]}{\partial b}>0 \quad \forall i=l, h \text { and } a_{-i}=S, I .
$$

Due to an increased income parameter, the conditions for an equilibrium of partial integration and total integration ((2), (3), and (4)) are satisfied more easily. In contrast, the condition for independence (1) is harder to satisfy.

The model confirms that the demand shift from desktop computers to laptops could have been the driving force for the acquisition wave. Since entry barriers into the semiconductor and computer industry are high, the demand shift strengthened market power of incumbent WLAN chip suppliers and allowed them to raise prices above marginal costs. According to Cournot (1960), the incentive

\footnotetext{
${ }^{21}$ The equilibrium industry structures are characterized in a comparative static analysis. Model parameters are a parameter denoting the fixed costs of integration $(\mathrm{F}>0)$, the quality parameters for the low-quality $\mathrm{CPU}\left(\mathrm{s}_{\mathrm{l}}>0\right)$ and for the typical WLAN chip $\left(\mathrm{s}_{\mathrm{j}}>0\right)$, the parameter denoting the relative quality distance between the CPUs ( $\left.>1\right)$, the parameter representing the number of WLAN chip suppliers ( $\mathrm{n} \geq 2)$ as well as the income parameter of the wealthiest consumer $(b>1)$.
} 
for horizontal M\&A is to internalize the externality associated with these price mark-ups. ${ }^{22}$ Furthermore, it is intuitive that the CPU suppliers' incentives for acquisitions are the larger, the higher the price-markups for WLAN chips are. Therefore, the conditions for partial integration and total integration are satisfied more easily:

$$
\text { (5) } \frac{\partial\left[v_{i}\left(a_{i}=I, a_{-i}\right)-v_{i}\left(a_{i}=S, a_{-i}\right)\right]}{\partial p_{n}^{\left(a_{i}=S, a_{-i}\right)}}>0 \quad \forall i=l, h \text { and } a_{-i}=S, I
$$

\section{Non-existence of the equilibrium of partial integration of the low-quality supplier:}

A general result of the model is that:

Lemma 1: All four industry structures are possible equilibrium outcomes within certain parameter regions. $^{23}$

Most interesting are the industry structures of partial integration:

Proposition 1: For a reasonably large product differentiation, an equilibrium industry structure of partial integration of the low-quality firm does not exist. In an equilibrium of partial integration, it is exclusively the high-quality firm, which is integrated.

\footnotetext{
${ }^{22}$ Independent suppliers for complementary products ignore that their price mark-ups reduce residual demand of each other. Thus, merging suppliers can profitably internalize this externality.

${ }^{23}$ See Westbrock (2004) for the proof.
} 
Proof: We infer from condition (2) that:

$$
v_{l}(I, S)-v_{l}(S, S)>v_{h}(I, I)-v_{h}(I, S)
$$

is a necessary condition for existence of the equilibrium of partial integration of the low-quality firm. However, for $s \geq s^{*}\left(n, s_{l}\right): v_{l}(I, S)-v_{l}(S, S)=v_{h}(I, I)-v_{h}(I, S)$, the condition cannot be satisfied. In contrast, the necessary condition for existence of the equilibrium of partial integration of the high-quality supplier is satisfied for all relative quality distances since:

$$
v_{h}(S, I)-v_{h}(S, S)>v_{l}(I, I)-v_{l}(S, I) \quad \forall s>1
$$

Given $s \geq s^{*}\left(n, s_{l}\right)$, an industry structure of partial integration of the superior supplier may be an equilibrium outcome in contrast to one of partial integration of the inferior firm.

Figure 1 depicts the proposition given $b=2, s_{l}=1, s_{j}=1$, and $n=23$. The $(F, s)$-space in the figure is divided into seven areas. Each area is marked with a big letter, and Table 4 describes the equilibrium, which results in the various regions. For $(\mathrm{F}, \mathrm{s})$ in regions $\mathrm{B}$ to $\mathrm{E}$, the equilibrium industry structure is partial integration. While two equilibria of partial integration are possible outcomes in region $\mathrm{C}$, partial integration of the high-quality supplier is the unique equilibrium in regions $\mathrm{B}, \mathrm{D}$, and $\mathrm{E}$. Thus, the industry structures of partial integration of either the superior or the inferior firm are possible equilibrium outcomes given $s<s^{*}$. However, if $s \geq s^{*}$, it is exclusively the high-quality firm, which is integrated in equilibrium. 


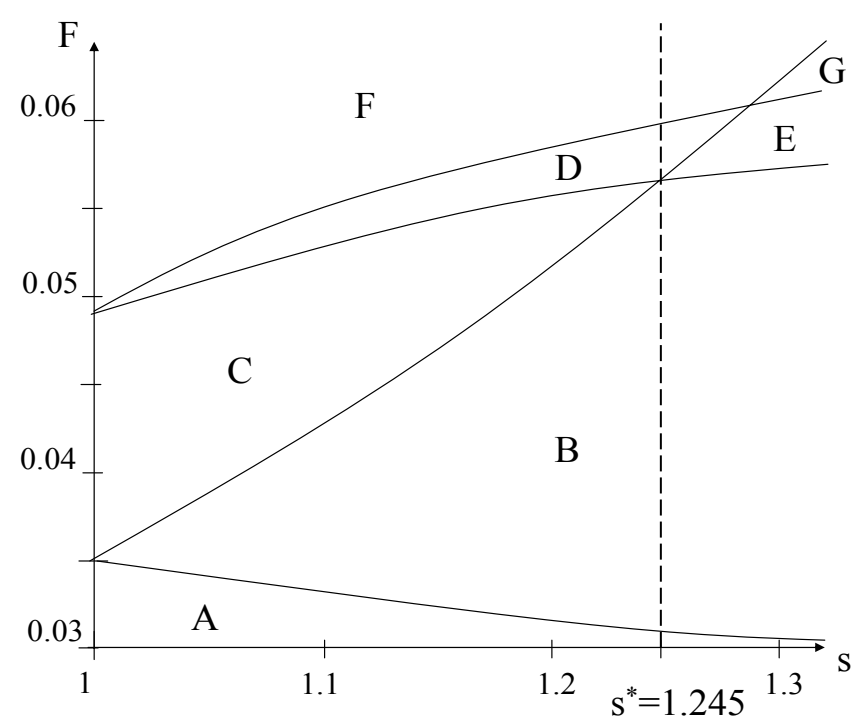

Figure 1: A comparative static analysis

\begin{tabular}{|ll|}
\hline \hline Region & Equilibrium industry structure \\
\hline A, D and E & Total integration \\
C & Partial integration of the high-quality firm \\
F and G & Two equilibria of partial integration \\
\hline \hline
\end{tabular}

Table 4: Description of the equilibrium industry structures

The proposition allows for conclusions about Intel's acquisition activities. The subset of parameters, resulting in equilibrium in regions $\mathrm{B}, \mathrm{D}$, and $\mathrm{E}$ to the right of $\mathrm{s}^{*}$ in Figure 1, could represent the situation in the component markets for CPUs and WLAN chips from 1999 to 2001. In that period, the technology leader Intel acquired various WLAN chip designers, while its competitors stayed independent. What is the economic rationale behind that? 


\section{The demand segmentation effect:}

In the industry structure of independence, the WLAN chip suppliers combine their chips with CPUs of Intel and sell them to the high-quality segment of demand. Additionally, they offer chips, combined with CPUs of AMD, to the low-cost segment. A single acquisition by one of the players causes three separable effects on the remaining independent suppliers in the WLAN chip market as well as on the market price.

The first two effects of the acquisition are contrary: on the one hand, an independent supplier is eliminated, which causes, ceteris paribus, the market price for WLAN chips to increase (the industry structure effect). On the other hand, by eliminating the horizontal externality, the integrated supplier offers more laptops than the previous independent firms. The output increase causes the demand of the remaining independent WLAN chip suppliers to shift back. Within our setup of linear demand curves, this produces a reduction of the market price for WLAN chips (the quantity expansion effect).

Due to the vertically differentiated product space, a third effect arises in the model. After the acquisition by the low-quality CPU supplier, for example, consumers choose between bundling a high-quality CPU and a WLAN chip, and purchasing an integrated low-quality bundle. Thus, the remaining independent WLAN chip suppliers are enabled to sell to the high-quality segment of demand. Since consumers in the segment have high payment reserves for laptops, the acquisition, ceteris paribus, raises the market price for WLAN chips (the demand segmentation effect). If, on the other hand, the superior firm is the one that acquires, the independent suppliers in the market for WLAN chips are forced to offer chips to the low-cost segment of demand. This causes the market price to decrease. 
Lemma 3: A vertically differentiated product space in the market of the acquiring firms affects the price in the target market due to a single acquisition by one of the firms (the demand segmentation effect). For a reasonably large relative quality distance and an acquisition by the low-quality supplier, the market price increases. It decreases if the high-quality supplier is the acquiring firm. The demand segmentation effect grows with increasing quality distance between the superior and the inferior products.

Proof: From the comparative static of the market price in Cournot competition with linear demand curves and constant marginal costs, we infer that the Cournot price increases with the price intercept of the inverse of total demand. ${ }^{24}$ The price intercepts of the inverses of total demand for WLAN chips satisfy under the different industry structures:

$$
\begin{array}{ll}
\bar{p}_{n-1}^{(I, S)}-\bar{p}_{n}^{(S, S)}=b \frac{s_{l} s_{j}\left(2 s^{2}-4 s+1\right)}{2 s}>0 & \forall s>1+\frac{1}{2} \sqrt{2} \\
\bar{p}_{n-1}^{(S, I)}-\bar{p}_{n}^{(S, S)}=-b \frac{s_{l} s_{j}(2 s-1)}{2 s}<0 & \forall s>1 .
\end{array}
$$

Thus, for relative quality distances of $s>1+\frac{1}{2} \sqrt{2}$ it holds true that:

$$
\bar{p}_{n-1}^{(I, S)}>\bar{p}_{n}^{(S, S)}>\bar{p}_{n-1}^{(S, I)}
$$

It also holds true that:

$$
\begin{aligned}
& \frac{\partial\left(\bar{p}_{n-1}^{(I, S)}-\bar{p}_{n}^{(S, S)}\right)}{\partial s}=b \frac{s_{l} s_{j}\left(2 s^{2}-1\right)}{2 s^{2}}>0 \\
& \frac{\partial\left(\bar{p}_{n-1}^{(S, I)}-\bar{p}_{n}^{(S, S)}\right)}{\partial s}=-b \frac{s_{l} s_{j}}{2 s^{2}}<0 .
\end{aligned}
$$

\footnotetext{
${ }^{24}$ While the Cournot price depends on the price intercept, it does not depend on the slope of a linear inverse demand function.
} 
Suppose AMD integrates into the WLAN chip market, and Intel stays independent (for the moment). AMD's acquisition increases the market price for WLAN chips. According to inequation (5), a higher market price causes a larger incentive of the independent player to acquire in reaction. For a quality distance of $s \geq s^{*}$, Intel's incentive equals or even exceeds AMD's. Then, in the simultaneous bargaining game of stage one, an equilibrium industry structure of partial integration of AMD is impossible.

\section{Social welfare}

In the section, the social desirability of the high-quality firm's acquisition is evaluated. We do this by comparing social surpluses associated with the industry structure of partial integration to the surpluses associated with a benchmark situation, which is equal in all characteristics except for the acquisition.

Proposition 2: The acquisition by the high-quality firm, which results in the equilibrium industry structure of partial integration, increases social welfare. For a reasonably large relative quality distance, the outside low-quality supplier takes advantage of the acquisition as a free rider.

Proof: Consumer surplus increases, which is indicated by the prices for both laptop computers:

(6) $\hat{p}_{l}^{(S, S)}+\hat{p}_{n}^{(S, S)}=b \frac{s_{l} s_{j}(s n+4 s-1)}{(1+n)(4 s-1)}>\hat{p}_{l}^{(S, I)}+\hat{p}_{n-1}^{(S, I)}=b \frac{s_{l} s_{j}(2 s n+2 s-1)}{2 n(4 s-1)}$

(7) $\hat{p}_{h}^{(S, S)}+\hat{p}_{n}^{(S, S)}=b \frac{s_{l} s_{j}\left(4 s^{3} n+4 s^{3}-2 s^{2} n+7 s^{2}-6 s+1\right)}{2(1+n)(4 s-1) s}>\hat{p}_{h}^{(S, I)}=b \frac{s_{h} s_{j}(4 s n-2 n+1)}{2 n(4 s-1)}$ 
Also, total surplus, net of fixed costs of integration, increases since:

$$
\begin{aligned}
& \Delta W_{\text {tot }}=s_{j}\left(s_{h}-s_{l}\right) \int_{\bar{\theta}^{(s, I)}}^{\bar{\theta}^{(s, s)}}(\theta d \theta)+s_{l} s_{j} \int_{\theta^{(s, I)}}^{\underline{\theta}^{(s, s)}}(\theta d \theta)-\max \{F: \hat{a}=(S, I)\}>0 \\
& s_{j}\left(s_{h}-s_{l}\right) \int_{\bar{\theta}^{(s, I)}}^{\bar{\theta}^{(s, S)}}(\theta d \theta)>0 \\
& S_{l} S_{j} \int_{\theta^{(s, I)}}^{\underline{\theta}^{(S, S)}}(\theta d \theta)>0 \\
& \max \{F: \hat{a}=(S, I)\}=v_{h}(S, I)-v_{h}(S, S) .
\end{aligned}
$$

Gross total surplus increases due to output expansion of both laptops. The low-quality supplier attracts new customers in the low-cost segment, and some consumers switch from the inferior to the superior laptop. The gross surplus gain even exceeds the maximum feasible waste of fixed costs, which affect an equilibrium of partial integration of the high-quality firm. The effect on the profit of the low-quality firm is ambiguous. For $s>s^{+}\left(n, s_{l}\right): \hat{\pi}_{l}^{(I, S)}=\hat{\pi}_{l}^{(s, S)}$, it is able to free ride.

The prices for laptop computers decrease, since the integrated high-quality supplier internalizes the horizontal externality and reduces the bundle price. Furthermore, this increases competition with rivals, and they react in price reductions as well (the quantity expansion effect). ${ }^{25}$ The vertically differentiated product space introduces an additional effect on the price for the low-quality laptop. The acquisition forces the remaining independent WLAN chip suppliers to sell to the low-cost segment of demand. Hence, it affects an additional price reduction (the demand segmentation effect). ${ }^{26}$ Contrary to the assumption that the technology leader Intel seeks to increase market power by acquiring, AMD takes the advantage of a free rider. The company benefits from the acquisition, because of the segmentation of demand and the fact that WLAN chips and CPUs are

\footnotetext{
${ }^{25}$ This strategic effect on consumer prices can be isolated from inequation (6) if $\mathrm{s}=1$ is assumed. Then, due to the acquisition, the price for the low-quality laptop decreases even without product differentiation.

${ }^{26}$ The demand segmentation effect on consumer prices works similar to third degree price discrimination in the market for WLAN chips. Under partial integration, the integrated WLAN chip unit sells exclusively chips to customers of high quality CPUs. Thus, it serves the demand segment with low price-elasticity for laptop computers in contrast to the independent suppliers for WLAN chips, which serve the high elasticity segment.
} 
(essential) complementary products. Obviously, the losers are the remaining independent suppliers for WLAN chips.

\section{Robustness}

The model, introduced in the previous sections, is of simple structure. It abstracts from several facts about the acquisition wave and neglects (consciously) more realistic scenarios presented in the literature. In the section, three critical assumptions are loosened, and the model results are examined for robustness to the variations. For analytical reasons, the effect of each partial variation is isolated. It is a general result of the chapter that the basic model is rather appropriate in representing the observed case, and that its major findings are of robust economic relevance.

\section{Selling separate components:}

A critical assumption of the basic model is that a horizontally integrated CPU supplier offers exclusively complete bundles. A more realistic scenario should incorporate that integrated firms could sell separate components as well. Such a scenario could violate the results of the model for two reasons: first, the integrated low-quality supplier could sell separate WLAN chips. This would lower the market price for WLAN chips in comparison to the basic model, because there is an additional supplier. Hence, the incentive of the superior supplier to acquire in reaction is reduced, and an industry structure of partial integration of the low-quality supplier could be a possible equilibrium outcome. Second, the integrated high-quality supplier could sell separate CPUs. This would raise the market price for WLAN chips in comparison to the basic model, because the suppliers in that market sell some of their chips to the high-quality segment of demand. Such a scenario could violate the social desirability of Intel's acquisition. 
In the following modification of the basic model, we allow the integrated suppliers to sell separate components and give an answer to two relevant questions. Does an integrated company have any incentive to offer separate components? And if so, does the scenario violate the results of the basic model $?^{27}$

Under partial integration of the low-quality supplier, the integrated firm may sell separate WLAN chips, which are denoted by $\mathrm{q}_{\mathrm{r}}$, in addition to its complete laptops, denoted by $\mathrm{q}_{1}$. Since its WLAN chips are of the same quality as the chips of the independent suppliers, the only attainable component price is $\mathrm{p}_{\mathrm{n}}$. At this market price, firms share total demand in equal proportions. Demand functions simply modify to:

$$
\begin{aligned}
& q_{l}=\frac{\left(p_{h}+p_{n}\right)-p_{l}}{s_{j}\left(s_{h}-s_{l}\right)}-\frac{p_{l}}{s_{j} s_{l}} \\
& q_{r}=q_{j}=\frac{1}{n} q_{n} \\
& q_{h}=q_{n}=b-\frac{\left(p_{h}+p_{n}\right)-p_{l}}{s_{j}\left(s_{h}-s_{l}\right)} .
\end{aligned}
$$

And the integrated firm's profit function changes to:

$$
\pi_{l}=q_{l} p_{l}+q_{r} p_{n}
$$

Calculation of equilibrium quantities and operating profits is analogue to the basic model:

$$
\begin{aligned}
& \widetilde{q}_{l}^{(I, S)}=b \frac{4 s+2 n s-1}{2(4 s-1)(1+n)}<\hat{q}_{l}^{(I, S)} \\
& \widetilde{q}_{r}^{(I, S)}=b \frac{2 s-1}{(4 s-1)(1+n)}>0 \\
& \tilde{\pi}_{l}^{(I, S)}=b^{2} \frac{s_{l} s_{j}\left(32 s^{3}+16 n s^{2}+8 s+4 n^{2} s^{2}-24 s^{2}-4 n s-1\right)}{4(4 s-1)^{2}(1+n)^{2}}
\end{aligned}
$$

By comparing operating profits of the integrated low-quality supplier under the basic and the modified model, we examine the incentive to sell separate WLAN chips. It can be shown that a minimum relative quality distance is necessary for offering separate components to be the dominant

\footnotetext{
${ }^{27}$ Of course, the low-quality supplier, for example, could sell separate CPUs instead of WLAN chips. However, this does not violate the findings of the model and therefore, is neglected within the modification.
} 
strategy. This is quite intuitive, since the low-quality supplier gains the more from selling WLAN chips to the high-quality demand segment, the higher the quality distance between CPUs is.

Thus, the scenario might violate the result that it is exclusively the superior supplier, which is integrated in an equilibrium of partial integration. However, Table 5 in the end of the section shows that under the modified model, just a marginally larger relative quality distance of $\mathrm{s}^{* *}$ is necessary for robustness of the result than the $\mathrm{s}^{*}$ of the basic model.

Under modified partial integration of the high-quality firm, consumers have three options: to buy an integrated high-quality bundle, or to combine either an inferior or a superior bundle on their own. Since both high-quality bundles are of homogeneous quality, consumers prefer the cheaper one. Thus, the integrated firm simply sets:

$$
p_{h}=p_{r}+p_{n-1}
$$

and the consumers' incentive compatibility constraint remains the same like in the basic model. Let $r \in[0,1]$ denote the proportion of separate CPUs in the product program of the integrated firm then, modified demand functions are:

$$
\begin{aligned}
& q_{l}=\frac{p_{h}-\left(p_{l}+p_{n-1}\right)}{s_{j}\left(s_{h}-s_{l}\right)}-\frac{\left(p_{l}+p_{n-1}\right)}{s_{j} s_{l}} \\
& q_{h}=(1-r)\left(b-\frac{p_{h}-\left(p_{l}+p_{n-1}\right)}{s_{j}\left(s_{h}-s_{l}\right)}\right) \\
& q_{r}=r\left(b-\frac{p_{h}-\left(p_{l}+p_{n-1}\right)}{s_{j}\left(s_{h}-s_{l}\right)}\right) \\
& q_{n-1}=q_{r}+q_{l} \\
& q_{j}=\frac{1}{n-1} q_{n-1} .
\end{aligned}
$$

The integrated firm's profit function changes to:

$$
\pi_{h}=q_{h} p_{h}+q_{r}\left(p_{h}-p_{n-1}\right)
$$

I modify slightly competition in quantities in the second stage of the game. The high-quality supplier decides about the proportion of separate CPUs before the WLAN chip suppliers set their 
quantities. This enables the integrated firm to raise total demand for WLAN chips. However, calculation of equilibrium quantities results in a proportion for separate CPUs of:

$$
\widetilde{r}=0 .
$$

Obviously, the integrated high-quality supplier does not have any incentive to sell separate chips, because it loses $p_{n-1}$ per unit in comparison to selling an additional complete bundle. In summary, the possibility to offer separate components in addition to complete bundles does not violate the results of the model.

\section{The holdout option in bargaining games:}

In the bargaining game of the basic model, CPU suppliers decide about acquiring or not. If they take over, they compensate the target WLAN chip supplier for the foregone profit that it received before the acquisition. Such a simple scenario underestimates the bargaining power of target firms in takeover negotiation. Consider a bet of the inferior firm under independence of the superior supplier. If it offers compensation in the amount of the basic model, the target firm is better off rejecting. Because of vertically differentiated CPUs, it gains from holding out and anticipating that another firm will be targeted since then, it is enabled to sell to the high-quality segment of demand. Unless the low-quality supplier does not bid enough to compensate for the lost opportunity, the bet fails.

However, such a more realistic bargaining situation does not violate the model result that it is exclusively the high-quality supplier, which is integrated in an equilibrium of partial integration. In contrast, it confirms it. If the low-quality supplier makes a bet under independence of the highquality firm, it has to compensate for the lost opportunity. Hence, it has a reduced incentive for acquiring in comparison to the basic model. There are even fewer cases, in which partial integration of the inferior supplier is an equilibrium outcome. In a negotiation with the superior firm, on the other hand, a target WLAN chip supplier does not want to hold out because then, it is forced to offer to the low-quality demand segment. Thus, its bargaining power remains unchanged like in the 
basic model. The reader might see that the simple bargaining game even emphasizes the robustness of the result that the high-quality supplier acquires in equilibrium. In this simple game, the condition for non-existence of the equilibrium of partial integration of the low-quality firm is hard to satisfy.

\section{More than a single acquisition:}

From 1999 to 2001, Intel acquired not just one but three of the former 23 independent firms in the market for WLAN chips. How can we rationalize the behavior? And what are the consequences for the application of the model results to the case?

In a model modification, the strategy of acquiring more than one firm is examined for its capability to foreclose the CPU market. The foreclosure effect of multiple acquisitions owes to the fact that additional independent suppliers in the market for WLAN chips are eliminated. This increases the market price (the industry structure effect of acquisitions), lowers revenues of the competitors in the CPU market and therefore, makes them softer in competition. ${ }^{28}$ Obviously, the social desirability of Intel's acquisition activities is threatened by foreclosure effects.

In a modified bargaining game of stage one, the superior firm may acquire more than one, but not all, suppliers for WLAN chips:

$$
A_{h}=\left\{I_{m}, S\right\} \quad, m \in[1, n-1]
$$

Let us assume that the low-quality supplier prefers to stay independent. Strategies therefore yield:

$$
\begin{array}{ll}
v_{h}\left(a_{h}, a_{l}=S\right)=\pi_{h}^{(S, S)} & \text { if } a_{i}=S \\
v_{h}\left(a_{h}, a_{l}=S\right)=\pi_{h}^{(S, I)}(m)-m \pi_{j}^{(S, S)}-F(m) & \text { if } a_{i}=I_{m} .
\end{array}
$$

\footnotetext{
${ }^{28}$ Church \& Ware (2000) provide a comprehensive summary about the incentive for market foreclosure. See Church \& Ware (2000), pp. 625-641.
} 
$\pi_{h}^{(S, I)}(m)$ denotes a more general version of operating profit than in the basic model with $\mathrm{m}$ instead of one eliminated firm:

$$
\pi_{h}^{(S, I)}(m)=b^{2} \frac{s_{h} s_{j}((m-n)(4 s-2)+1-4 s)^{2}}{4(4 s-1)^{2}(m-n-1)^{2}}
$$

Assuming that fixed costs of integration do not depend on the number of acquisitions $(F(m)=F(1))$, we calculate the privately optimal strategy. It depends on the trade-off between the industry structure effect and additional compensation payments.

It can be shown that acquiring $\widetilde{m}=1$ firms is the dominant strategy in some parameter regimes and acquiring $\widetilde{m}=n-1$ firms in others. ${ }^{29}$ The former strategy is the one of the basic model and results in price reductions for both types of laptops. The latter raises laptop prices and it might therefore violate the social desirability of Intel's acquisitions.

However, the strategies $m \in[2, n-2]$, and especially Intel's $m=3$, are dominated in all regimes. Moreover, for relative small $\mathrm{m}$ (in comparison to $\mathrm{n}$ ) like $\mathrm{m}=3$, the market price for WLAN chips as well as the prices for both laptops decrease. Hence, Intel's three acquisitions seem not to be driven by foreclosure intentions. If the company had intended to foreclose the CPU market to AMD, VIA, or Transmeta, it should have been involved in more acquisitions. ${ }^{30}$

\footnotetext{
${ }^{29}$ If fixed costs of integration increase not too slow in the number of acquisitions, $\widetilde{m}=1$ dominates in all regimes.

30 An alternative approach to a rationale for Intel's three acquisitions could be the intention to avoid capacity restrictions by integrating more than one of the small WLAN chip suppliers.
} 


\begin{tabular}{|l|llll|}
\hline \hline $\mathrm{F}$ & $>0$ & $>0$ & $>0$ & $>0$ \\
$\mathrm{~b}$ & $>1$ & $>1$ & $>1$ & $>1$ \\
$\mathrm{n}$ & 3 & 23 & 23 & 23 \\
$\mathrm{~s}_{\mathrm{j}}$ & 1 & 1 & 10 & 10 \\
$\mathrm{~s}_{1}$ & 1 & 1 & 1 & 10 \\
\hline $\mathrm{s}^{*}$ & 1.05 & 1.24 & 1.24 & 1.24 \\
$\mathrm{~s}^{* *}$ & 1.18 & 1.3 & 1.3 & 1.3 \\
$\mathrm{~s}^{+}$ & 1.26 & 1.26 & 1.03 & 1.03 \\
\hline \hline
\end{tabular}

Table 5: Summary of the critical quality distances for various parameters 


\section{Summary and conclusion}

M\&A activities in the semiconductor and computer industry of the 1990 s concentrated on the technology leaders. The paper investigates the influence of players' heterogeneous product technologies on their involvement in M\&A within a case study about a wave of acquisitions between suppliers for CPUs and WLAN chips. The technology leader Intel started the wave and dominated with three major deals. A game theoretical model, which characterizes players' technologies within a vertically differentiated product space, investigates the influence. Central to the model is that in the equilibrium industry structure of partial integration, it is exclusively the high-quality supplier, which is integrated. The rationale for the result is that an acquisition by one of the players causes the remaining independent firms in the target market to serve a certain demand segment. Contrary to the assumption that the technology leader seeks to increase market power, its acquisitions increase social welfare and allow low-quality rivals to enjoy a free ride.

From the application of the model to the case of the two component markets, we can generalize about M\&A in the semiconductor and computer industry. It is typical in the industry, that next generation chip technologies displace older ones in well defined performance categories. Thus, semiconductor and computer components are positioned in a vertically differentiated product dimension like in the market for CPUs. The model predicts that the technology leader in a specific component market will be involved in M\&A if just some, but not all, suppliers are. Moreover, consortia like the IEEE ensure compatibility of components' interfaces in the semiconductor and computer industry. Hence, a component brand could technically be combined with each brand in another component market like the WLAN chips. However, the decision to integrate components into bundles restricts technically feasible product combinations and segments demands within the component markets. 


\section{References}

Church, J. and Gandal, N. (2000): Systems Competition, Vertical Mergers and Foreclosure, in: The Journal of Economics \& Management Strategies, Vol. 9, No.1 (Spring2000), pp. 25-51.

Church, J. and Ware, R. (2000): Industrial Organization: A Strategic Approach, New York, McGraw-Hill, 2000.

Cournot, A.A. (1960): Researches into the Mathematical Principles of the Theory of Wealth, 1838, Translation of N.T. Bacon, New York: Kelley, A.M, 1960.

Computer Technik (2002): AMD gegen Intel: Duell um Markt und Technik, in: C't: Magazin für ComputerTechnik, Vol. 13 (2002), pp. 98-102.

Economides, N. (1994): The incentive for vertical integration, mimeo EC-94-05, Stern School of Business, N.Y.U., NewYork.

Economides, N. and Salop, S.C. (1992): Competition and Integration among Complements, and Network Market Structures, in: The Journal of Industrial Economics, Vol. 40, No.1, pp. 105123.

Federal Trade Commission (2004): In the Matter of Intel Corporation: Administrative Complaint, http://www.ftc.gov/os/1998/intelfin.cmp.htm, retrieved on: 2004-04-15.

Gabszewicz, J.J. and Thisse, J.-F. (1979): Price Competition, Quality and Income Disparities, Journal of Economic Theory, Vol. 20, pp. 340-359.

Institute of Electrical and Electronics Engineers (2004): Intellectual Properties and Patents: IEEE IP Policy, http://www.ieee802.org/11/, retrieved on: 2004-03-12.

Macher, J., Mowery, D.C. and Hodges, D. (1998): Reversal of Fortune? The Recovery of the U.S. Semiconductor Industry, in: California Management Review, Vol. 41, Issue 1, pp. 107-136.

Organization for Economic Co-Operation and Development (2002): OECD Information Technology Outlook: ICTs and the Information Economy, Paris, 2002.

Shaked, A. and Sutton, J. (1982): Relaxing Price Competition through Product Differentiation, in: Review of Economic Studies, Vol. 49, pp 3-13. 
Shapiro, C. (1989): Theories of Oligopoly Behavior, in: Schmalensee, R., Willig, R. (eds.): Handbook of Industrial Organization, Vol. 1, Elsevier Science Publishers, 1989, pp. 330-414. Tech Europe (2004): Computers: World Laptop Market goes from Strength to Strength, http://web.lexis-nexis.com/professional/, retrieved on: 2004-03-12.

Tom's Hardware Guide (2004): Tom's Guides: Processors, http://www17.tomshardware.com/cpu/index.html, retrieved on: 2004-08-22.

Tirole, J. (1988): The theory of industrial organization, The MIT Press, 1988.

Westbrock, B. (2004): Horizontal integration in markets for complementary inputs: a case based analysis in the semiconductor component industry, diploma thesis submitted at the Department of Economics, University of Mannheim, 2004. 